\section{Tropical Journal of Pathology and Microbiology}

\title{
The utility of Fine Needle Aspiration Cytology in the Diagnosis of Lymphadenopathy
}

\author{
Elizabeth Prakash A. ${ }^{1 *}$, Narayanano N. ${ }^{2}$, Pokkakillath Mohamed S. ${ }^{3}$, Unnikrishnan R. ${ }^{4}$ \\ DOI: https://doi.org/10.17511/jopm.2020.i08.03 \\ 1* Annu Elizabeth Prakash, Assistant Professor, Department of Pathology, Sree Narayana Institute of Medical Sciences, Ernakulam, Kerala, \\ 2 Navya Narayanano, Associate Professor, Department of Pathology, Sree Narayana Institute of Medical Sciences, Ernakulam, Kerala, India. \\ 3 Siyad Pokkakillath Mohamed, Consultant, Department of pathology, Westfort Hospital, Thrissur, Kerala, India. \\ ${ }^{4}$ Rasmi Unnikrishnan, Assistant Professor, Department of Pathology, Sree Narayana Institute of Medical Sciences, Ernakulam, Kerala, India.
} India.

Introduction: The causes of lymphadenopathy may be varied ranging from reactive to neoplastic. Fine Needle Aspiration Cytology(FNAC) is a simple and inexpensive diagnostic tool to sample cells from superficial and accessible sites. Aims: This study was undertaken to assess the utility of FNAC in evaluating lymphadenopathy and to study the cytomorphological spectrum of lymph node lesions in our region. Settings and Design: A cross-sectional study of two years duration, on patients with lymphadenopathy who came to the Pathology Department for FNAC. Methods and materials: Cytology findings of Lymph node lesions were classified into four categories and were compared with histopathology diagnosis as the gold standard. Statistical Analysis: Data was tabulated according to various parameters. Sensitivity, Specificity, PPV, NPV, and Diagnostic accuracy for detecting malignancy were calculated. Results: The age range of patients included in the present study ranged from 9 to -78 years. The mean age is 48.92 years and the median is 52 years. The cytological diagnosis was classified as reactive in 20 cases $(32.7 \%)$, inflammatory in 16 cases $(26.2 \%)$, lymphoma in 3 cases $(4.9 \%)$, and 22 cases $(36.1 \%)$ were metastasis from other sites. Following histopathology, the cases were diagnosed to be 19 reactive lymphadenopathies, 14 inflammatory lesions, 5 lymphomas, and 23 metastasis. The most common site of lymphadenopathy was the cervical region. Conclusions: FNAC has high sensitivity and specificity in differentiating benign lesions from malignant ones. The age, clinical findings, and supporting investigations should be taken into account while diagnosing a lesion as benign or malignant.

Keywords: Fine needle aspiration cytology, Granulomatous lymphadenitis, Lymphadenopathy, Lymph node metastasis

Corresponding Author

Annu Elizabeth Prakash, Assistant Professor, Department of Pathology, Sree Narayana Institute of Medical Sciences, Ernakulam, Kerala, India. Email: annelizprakash@gmail.com
How to Cite this Article

To Browse

Prakash AE, Narayanano N, Mohamed SP, Unnikrishnan R. The utility of Fine Needle Aspiration Cytology in the Diagnosis of Lymphadenopathy. Trop J Pathol Microbiol. 2020;6(8):472-480. Available From https://pathology.medresearch.in/index.php/jopm/ar ticle/view/496

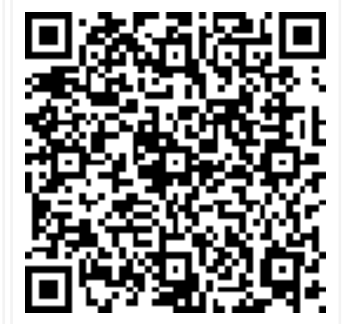

Manuscript Received 2020-11-11

Conflict of Interest No
Review Round 1 2020-12-09

Funding $\mathrm{Nil}$

Review Round 2
2020-12-19
Ethical Approval
Yes

Review Round 3

Plagiarism X-checker $6 \%$
Accepted

2020-12-18

(c) 2020 by Annu Elizabeth Prakash, Navya Narayanano, Siyad Pokkakillath Mohamed, Rasmi Unnikrishnan and Published by Siddharth Health Research and Social Welfare Society. This is an Open Access article licensed under a Creative Commons Attribution 4.0 International License https://creativecommons.org/licenses/by/4.0/ unported [CC BY 4.0].
Note 


\section{Introduction}

Lymph nodes are secondary lymphoid organs, inconspicuously distributed throughout the body. Lymphadenopathy is a common complaint in children and adults alike, encountered often in routine medical practice. As an antigen, whether infectious or neoplastic in origin, picked up by Antigen Presenting Cells from different sites ultimately reach the draining nodes, the causes of lymphadenopathy vary as much as the sites.

FNAC is a simple and inexpensive investigation by which cells can be sampled from accessible tissues for cytomorphological study. The efficacy of fineneedle aspiration in the evaluation of lymphadenopathy has been known since the early years of the twentieth century. It is ideal as a preliminary investigation in determining the nature of the disease and providing a guideline to the clinician in further investigations and management [1]. The shorter turnaround time for cytology also recommends it to clinicians as a diagnostic tool. The limitations of FNAC include the difficulty in interpretation in the case of heterogeneous lesions and the lack of a specific architectural pattern as in histology.

Excision biopsy, although more reliable for a final diagnosis, is associated with unavoidable expenses due to hospitalization and preparation for a surgical procedure and the ensuing complications [2].

This study was undertaken to assess the utility of FNAC in evaluating lymphadenopathy and the cytomorphological spectrum of lymph node lesions in our region.

\section{Materials and Methods}

Type of Study: Retrospective chart review

Settings: Department of Pathology of a tertiary care teaching hospital in Central Kerala

Duration of study: Four months

Sampling method: Purposive sampling

Sample size: A total number of 73 cases of lymphadenopathy underwent FNAC during this period of which 61 cases that fulfilled the criteria were included in the study

Inclusion criteria: Cases of patients who underwent FNAC and histopathology for lymphadenopathy
Exclusion criteria: Cases of lymphadenopathy in which cytology smears were inadequate for a definite diagnosis

Data collection procedure: All the cytology slides of cases of lymphadenopathy from January 2017 to December 2018 (2 years) were retrieved from the archives of the Department of Pathology. This included wet fixed smears stained with Hematoxylin and Eosin (1-2 slides) and Papanicolau stain (1 slide) and dry smears (1 slide) stained with Giemsa stain. The clinical history of the patients was retrieved from medical records. On examining the smears, cellularity, nuclear and cytoplasmic features, and the background were evaluated.

The cytological diagnoses were broadly categorized as reactive, inflammatory, lymphoma, and metastatic malignancy. The histopathology slides of these cases were also retrieved. The histopathology diagnoses were correlated with that of cytology. Histopathology diagnosis was considered as the gold standard in case of discrepancy.

Ethical consideration and permission: Permission was obtained from the departments concerned for retrieving the patient slides and medical records. Confidentiality about the patients was maintained throughout.

Statistical analysis: Statistical analysis was done using Microsoft Excel 2010. Categorical variables were presented as absolute numbers and percentages. All malignant cases were considered as positive and all non-malignant cases were considered as negative for analysis.

Taking histopathology as the gold standard, true positives, true negatives, false positives, and false negatives in each category were identified. The diagnostic reliability of cytology as a diagnostic tool was assessed by calculating the sensitivity, specificity, positive predictive value, and negative predictive value.

\section{Results}

Among the 61 cases included in the present study, 29 were males and 32 were females, with a male: female ratio of $1: 1.1$.

The age range of patients included in the present study ranged from 9 to -78 years. The mean age is 48.92 years and the median is 52 years. Only $7 / 61$ $(11.5 \%)$ cases were from patients less than 20 years of age. 
Fourteen cases (22.9\%) belonged to the age group $20-39$ years and 17 cases (27.9\%) to the age group 40-59 years. The greatest caseload belonged to the elderly population, age group 60-79 years, totaling 23 cases $(37.3 \%)$. The age-sex distribution of patients is shown in Table 1 . The most common site of lymphadenopathy in the present study was the cervical region, accounting for 34 cases (55.7\%), followed by the axillary region accounting for 8 cases $(13.1 \%)$. The other sites included in the present study were supraclavicular, inguinal, submandibular, parotid, submental regions. Cervical lymph nodes predominantly showed reactive and inflammatory lesions whereas metastatic disease was more common in axillary and supraclavicular regions. The distribution of the different types of the lesion according to the lymph node site is detailed in Table 2.

Table-1: Age sex Distribution.

\begin{tabular}{|c|c|c|c|}
\hline \multicolumn{4}{|c|}{ Age sex distribution } \\
\hline \multirow[t]{2}{*}{ Age group } & \multicolumn{2}{|l|}{ gender } & \multirow[t]{2}{*}{ Total } \\
\hline & $F$ & M & \\
\hline $0-9$ & 0 & 1 & 1 \\
\hline 10 to 19 & 3 & 3 & 6 \\
\hline $20-29$ & 4 & 0 & 4 \\
\hline 30-39 & 5 & 5 & 10 \\
\hline $40-49$ & 1 & 3 & 4 \\
\hline $50-59$ & 7 & 6 & 13 \\
\hline $60-69$ & 8 & 9 & 17 \\
\hline 70-79 & 4 & 2 & 6 \\
\hline Total & 32 & 29 & 61 \\
\hline
\end{tabular}

Table-2: Relationship between the site of lymphadenopathy and category of the lesion.

\begin{tabular}{|c|c|c|c|c|c|}
\hline \multirow[t]{2}{*}{ Site } & \multicolumn{4}{|c|}{ Category of lesion } & \multirow[t]{2}{*}{ Total } \\
\hline & I & $\mathrm{L}$ & M & $R$ & \\
\hline Axilla & 1 & 1 & 4 & 2 & 8 \\
\hline Cervical & 12 & 3 & 8 & 11 & 34 \\
\hline Inguinal & 0 & 1 & 2 & 2 & 5 \\
\hline Parotid & 0 & 0 & 0 & 1 & 1 \\
\hline Submandibular & 0 & 0 & 3 & 2 & 5 \\
\hline Submental & 0 & 0 & 0 & 1 & 1 \\
\hline Supraclavicular & 1 & 0 & 6 & 0 & 7 \\
\hline Total & 14 & 5 & 23 & 19 & 61 \\
\hline
\end{tabular}

The cytological diagnosis was benign in $35 / 61$ cases of which 20 cases $(32.7 \%)$ were reactive and 16 (26.2\%) showed inflammatory lesions. Of the $26 / 61$ cases with a cytological diagnosis of malignancy, 3 cases $(4.9 \%)$ were primary lymphoid neoplasms and 22 cases $(36.1 \%)$ were metastasis from other sites.
Following histopathology, the cases were diagnosed to be 19 reactive lymphadenopathies, 14 inflammatory lesions, 5 lymphomas, and 23 metastasis.

Inflammatory lesions were predominant in 20-39 years whereas metastatic malignancy was the most common cause for lymphadenopathy in the elderly (60-79 years). Reactive lymphadenopathy was evenly distributed among all age groups. Lymphoma as a cause of lymphadenopathy was most evident in the age group 40-59 years. The most common cytology diagnosis in the entire study population was reactive lymphadenopathy (19 cases, $31.1 \%$ ), followed by granulomatous lymphadenitis ( 8 cases, $13.1 \%)$.

Only one case among the five lymphoma cases was that of Hodgkin lymphoma. Others were diagnosed with Non-Hodgkin Lymphoma on cytology. These cases were diagnosed as Diffuse Large B cell lymphoma, Small cell Lymphoma, Follicular Lymphoma, and T cell lymphoma on histopathology followed by immunohistochemistry. Among the 23 cases of metastatic malignancy, the most frequent lesion was Squamous Cell Carcinoma (10 cases, $16.39 \%$ ) and followed by Adenocarcinoma (4 cases, $6.56 \%$ ). The other malignancies showing metastasis included ductal adenocarcinoma of breast (3 cases), Malignant Melanoma ( 2 cases), Mucoepidermoid carcinoma, and Odontogenic carcinoma (1 case each), among others.

Three cases were false negative for malignancy. No false-positive cases were present in the present study. One of the false-negative cases was in the reactive group on cytology, which was diagnosed to be Non-Hodgkin lymphoma on biopsy. The remaining two cases belonged to the inflammatory group. A case diagnosed as granuloma on cytology turned out to be Hodgkin lymphoma, and a case that showed only necrosis was diagnosed as metastatic Squamous cell carcinoma. Taking histopathology diagnosis as the gold standard, the sensitivity, specificity, positive predictive value, negative predictive value, and diagnostic accuracy of FNAC in diagnosing malignancy were $89.29 \%$, $100 \%, 100 \%, 91.67 \%$, and $95.08 \%$ respectively.

\section{Discussion}

Lymphadenopathy is a clinical finding seen in patients of varying age groups. It may be associated with underlying conditions ranging from inflammatory to neoplastic. 
FNAC is an ideal first-line investigation of cervical lymphadenopathy and has proven to be extremely helpful in differentiating benign from malignant conditions [1]. FNAC may be the first indicator of metastatic disease and is also instrumental in identifying the nature and origin of the primary tumor [3].

A maximum number of cases in the present study fell in the elderly age group, in contrast to similar Indian studies, which showed the predominance of the younger age group $[2,3,4,5]$. This discrepancy might be because, our institution is situated in a comparatively affluent region, with better standards of living, cases of granulomatous lymphadenitis were fewer in number and metastatic malignancies were more.

Tuberculous lymphadenitis accounts for more cases of lymphadenopathy in young adults as reported by Nidhi et al [6]. Metastatic malignancies were more prevalent in the elderly age group in similar studies $[3,7]$.

Female patients were more in the present study (M: $\mathrm{F}=1: 1.1$ ), as in studies by Nidhi et and Ageep et al, which also showed a similar sex ratio $[6,8]$. Most of the Indian studies with the same background showed male predominance $[1,2,3,4]$.

Most common sites of lymphadenopathy encountered in the present study corresponded with the pattern observed by Hemalatha et al and Bhosale et al $[9,10]$. In other similar studies, the most frequent cause for lymphadenopathy in all the sites was Tuberculosis, but in the present study Lymphadenopathy classified as inflammatory including granulomatous lymphadenitis was the most important etiology only in the cervical group of lymph nodes.

Reactive hyperplasia (20/61 cases) is a non-specific form of lymphadenopathy with varying etiological factors. The cytomorphology also varies depending on the extent of stimulation of the lymph node and the region of the lymph node from where the aspirate was obtained. Aspirate from a reactive lymph node is characterized by high cellularity, the polymorphous population of lymphoid cells, and the presence of tingible body macrophages [4].

One of the cases classified on cytology as reactive was diagnosed as a case of Non-Hodgkin Lymphoma on follow up. Cytology was misleading with a mixed lymphoid pattern with histiocytes and tingible body macrophages (Figure 1).

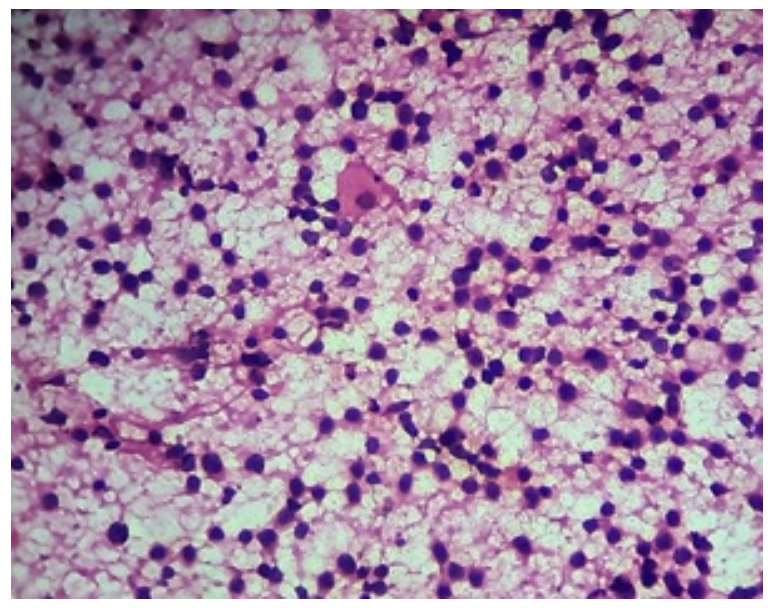

Fig-1: False-negative case- Axillary lymph node diagnosed, as reactive on cytology, and as Non-Hodgkin Iymphoma on Histopathology ( $H$ and $E, 40 X$ ).

The histopathology slide showed partial involvement of the node by Diffuse large $B$ cell lymphoma. Stewart et al conclude that the accuracy of lymphoma diagnosis by FNAC depends upon the proportion of primary to recurrent lymphoma diagnosed by cytology. In case of heightened clinical suspicion of lymphoid malignancy, the neoplastic cells are more easily identified. Another cause for false negativity is the partial involvement of nodes by lymphoma, as in our case [11].

The category of inflammatory lesions in the present study included suppurative inflammation and granulomatous inflammation with or without caseation necrosis. Suppurative lymphadenitis could be due to localized infections by pyogenic bacteria. One of the cases under was classified as suppurative lymphadenitis on cytology, which on repeat FNAC after supportive treatment yielded a diagnosis of granulomatous lymphadenitis (Figure $2 \mathrm{a}$ and $2 \mathrm{~b}$ ).

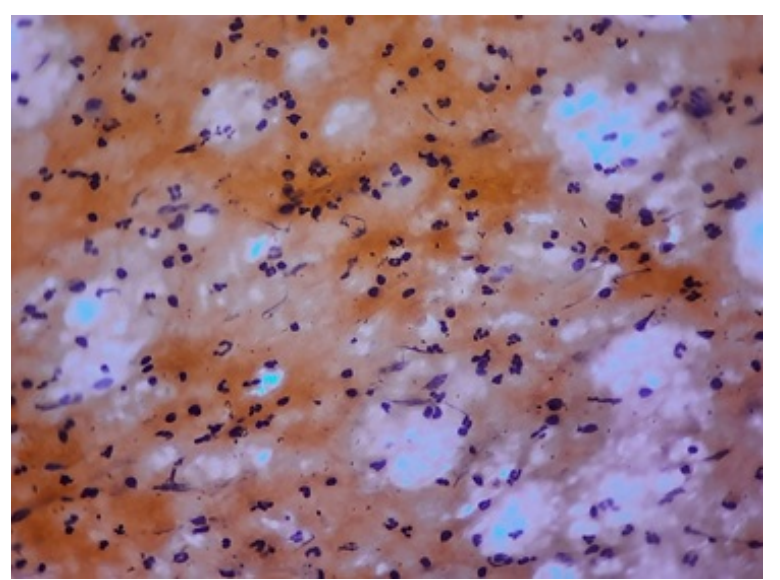


Fig-2a: Suppurative lymphadenitis in a 19year-old female (Pap, 40X).

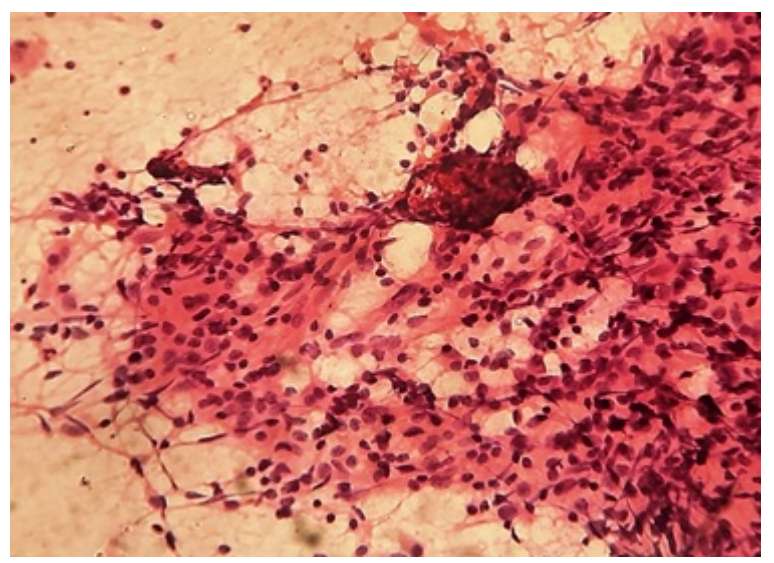

Fig-2b: Cytology of the same patient after 1 year, showing granuloma ( $H$ and $E, 40 X$ ).

Hemalatha et al advise mandatory AFB staining on aspirating purulent material to avoid this contingency [9]. Nidhi et al described four cytomorphological patterns in tuberculous lymphadenitis, namely, epithelioid granulomas with caseous necrosis, epithelioid granulomas without necrosis, necrosis only without granulomas, and polymorphs with granulomas [6]. This study reported AFB positivity in $71 \%$ of cases, mostly in those showing necrosis only without granulomas. Activated macrophages forming granulomas effectively neutralize mycobacteria and hence few sides with granulomatous reaction show AFB. Where macrophage reaction is weak, more tissue destruction occurs by caseous necrosis and these necrotic areas reveal abundant bacilli [9]. Studies in developed countries report neoplastic as well as infective etiology in granulomatous lymphadenitis, but since India has a high disease burden of Tuberculosis, the primary diagnosis considered in a case of granulomatous lymphadenitis is tuberculosis $[9,12]$.

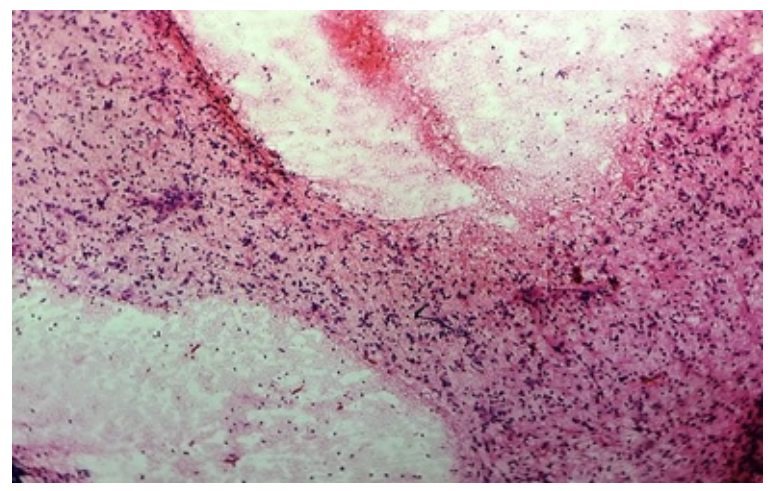

Fig-3: False-negative- Cytology diagnosed as granuloma in a young male with cervical lymphadenopathy, histopathology showed Hodgkin Lymphoma. (H and E, 10X).

A case diagnosed as granulomatous lymphadenitis in a 19-year-old male was identified as Hodgkin Lymphoma on histopathology (Figure 3).

Several hematological and non-hematological malignancies show granulomatous response as a result of antigens derived from tumor cells triggering a hypersensitivity reaction [12]. An exuberant granulomatous reaction may mask the diagnostic features of malignancy as occurred in our case. Mononuclear RS cells are difficult to distinguish from atypical immunoblasts also.

Another case of lymphadenopathy which showed necrotic material only on cytology was also classified as inflammatory. On histopathology, metastatic squamous cell carcinoma was detected. (Figure $4 \mathrm{a}$ and $4 \mathrm{~b}$ )

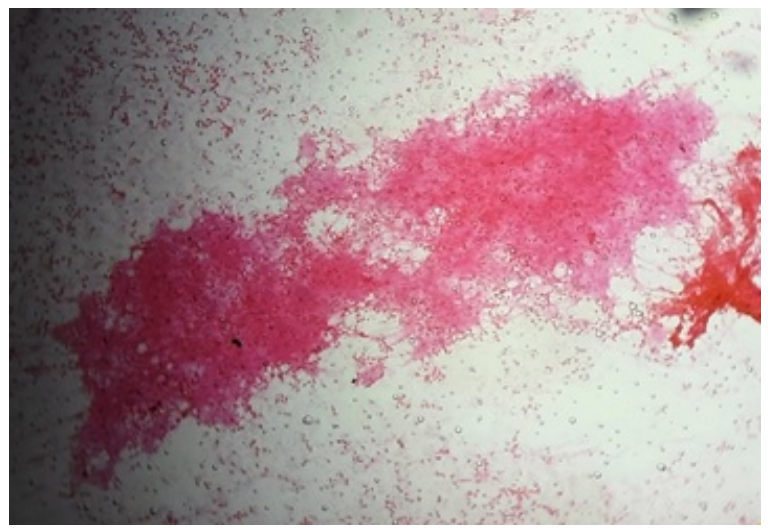

Fig-4a: Cytology of cervical lymph node showing necrotic material only. (Pap, 10X).

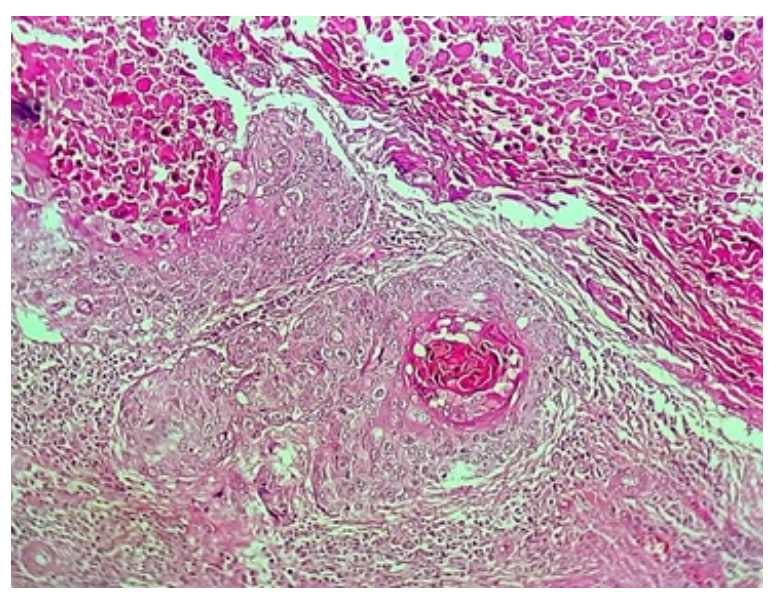


Fig-4b: Histopathology showing Metastasis from Squamous cell carcinoma with large areas of necrosis ( $H$ and $E, 40 X$ ).

Hemalatha et al advocate that on aspirating purulent material in elderly patients with lymphadenopathy, an intense search should be done for squamous cell carcinoma deposits, and accompanied by relevant history taking and local examination. Deposits from Squamous cell carcinoma have been known to cause liquefactive necrosis of lymph nodes resulting in greenish discharge [9].

Two cases of Small Cell Lymphoma and one case of Follicular lymphoma were diagnosed as NonHodgkin Lymphoma on cytology and the diagnosis was confirmed on histopathology. The relatively monomorphous lymphoid population (Figure 5) in contrast with the polymorphous population seen in reactive proliferation is instrumental in recognizing low-grade lymphomas [11].

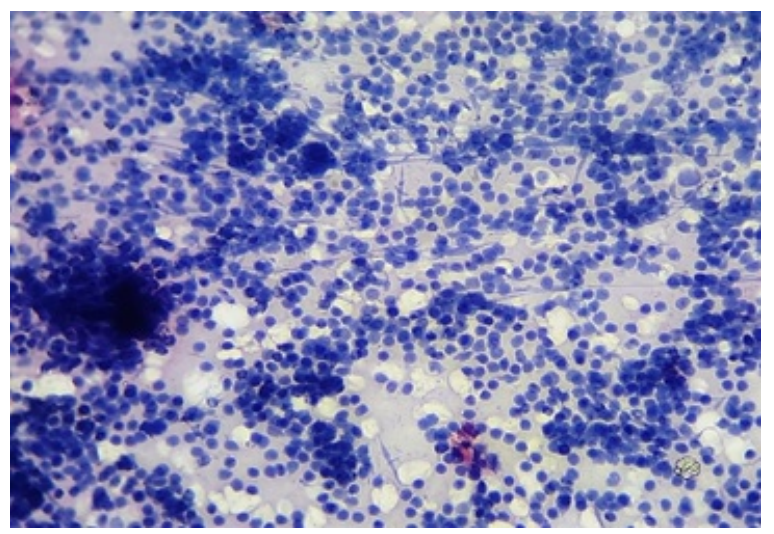

Fig-5: Monomorphous Iymphoid population in lymphoma ( Pap, 40X).

The most common metastatic malignancy in the present study was Squamous Cell Carcinoma, followed by adenocarcinoma as in Indian studies on metastatic lymphadenopathy $[3,7]$. Vartak et al reported infiltrating ductal carcinoma as the third most common metastatic lesion, all in known cases of carcinoma breast, as also in the present study [7].

Squamous cell carcinoma shows the cervical group of lymph nodes as the most frequent site of metastasis, similar to the results in a study on malignant lesions in lymph nodes [13]. The diagnostic challenges in squamous cell carcinoma occur due to large areas of necrosis and cystic change, inflammatory reactions, and abscess formation [14].
One case of submandibular lymphadenopathy diagnosed on cytology as Squamous cell carcinoma based on cytomorphological features, on excision turned out to be a case of odontogenic carcinoma. (Figure 6a and 6b) Clear cell odontogenic carcinoma is an aggressive tumor with reported cervical lymph node metastasis. Ameloblastomatous pattern of clear cell odontogenic carcinoma shows cells with squamous differentiation, which was noted in the cytology of this case [15].

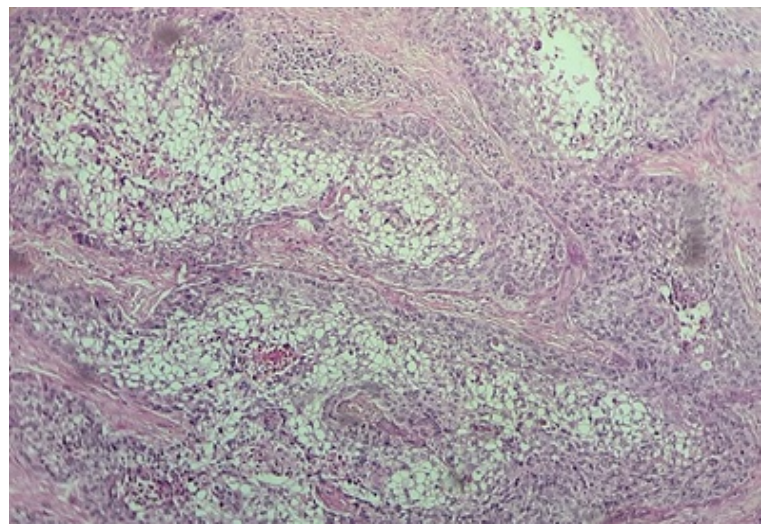

Fig-6a: Discordant case- Cytology diagnosed as a metastasis from squamous cell carcinoma. (Pap, 40X).

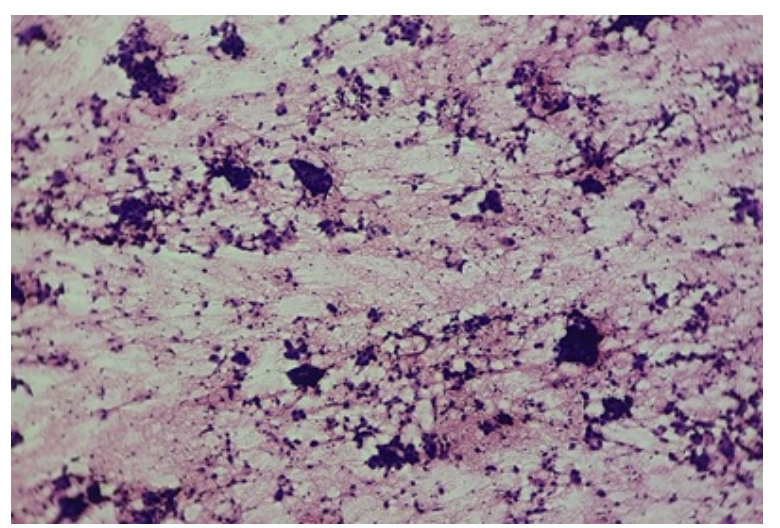

Fig-6b: Histopathology of the same case reported as Clear cell Odontogenic Carcinoma ( $H$ and $E$, 40X).

Metastasis from adenocarcinoma was noted more in supraclavicular lymph nodes. The acinar and papillary pattern of arrangement pointed to the diagnosis in most of the cases (Figure 7), as in the study on metastatic lymph nodes by Ghartimagar et al. Adenocarcinoma appeared to be the most common malignancy in this study, unlike the present study in which squamous cell carcinoma preceded adenocarcinoma in frequency [16]. 
Infiltrating ductal carcinoma was found metastasising to axillary lymph nodes in three known cases of carcinoma breast.

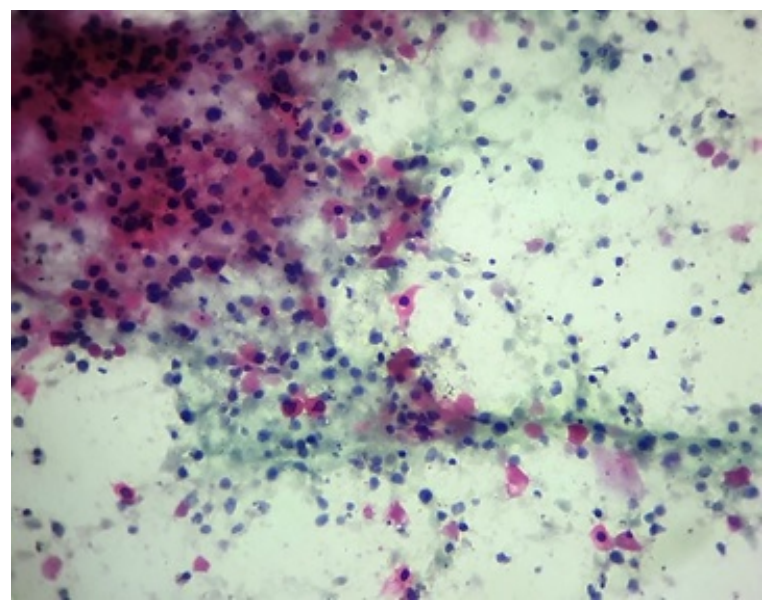

Fig-7: Cytology of adenocarcinoma, showing acinar and papillary pattern ( $H$ and $E, 10 X)$.

Two cases of metastatic Malignant Melanoma were included in the present study of which one was reported as mere metastasis from spindle cell neoplasm as pigmented cells were not found on cytology. The other case showed cells with cytoplasmic melanin (Figure 8) and the diagnosis was made easily, and subsequently, a previous history of melanoma was elicited.

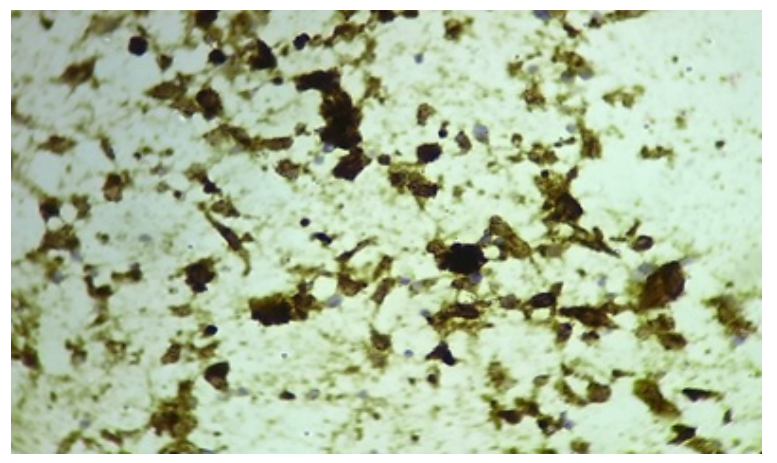

Fig-8: Pigmented cells of metastatic melanoma (Pap, 40X).

The characteristic cytology of malignant melanoma includes high cells yield with varying cell morphology, dissociated pattern, anisokaryosis with macronuclei. Cytoplasmic melanin pigment is a clinching feature but may not be always evident. Misdiagnosis can be avoided by eliciting an appropriate clinical history [17].

Other cases of metastasis included poorly differentiated carcinoma metastasizing to cervical and supraclavicular lymph nodes and
Mucoepidermoid carcinoma to a submandibular node. The site of metastasis of these neoplasms correlates well with those in similar studies $[7,13]$.

The sensitivity and specificity of FNAC in diagnosing malignancy correlates well with these parameters in similar studies. (Table 3) $[18,19,20]$. Diagnostic accuracy stays within the range proposed by Wilkinson et al. in a study of lymph node malignancies [13]. Positive predictive value is similar to and negative predictive value higher in our as compared to similar studies, as no falsepositive case is reported in the present study [18].

Table-3: Comparison of Statistical Parameters with similar studies.

\begin{tabular}{|l|l|l|l|l|}
\hline $\begin{array}{c}\text { Statistical } \\
\text { parameters }\end{array}$ & $\begin{array}{c}\text { Present } \\
\text { study }\end{array}$ & $\begin{array}{c}\text { Hafez et al } \\
{[\mathbf{2 0}]}\end{array}$ & $\begin{array}{c}\text { Kamaal et al } \\
{[\mathbf{1 8}]}\end{array}$ & $\begin{array}{l}\text { Hirachand et a } \\
{[\text { 19] }}\end{array}$ \\
\hline Sensitivity & 89.29 & 90.9 & 75 & $80-100 \%$ \\
\hline Specificity & 100 & 67.2 & 75 & $95.65-100 \%$ \\
\hline PPV & 100 & 82.6 & 100 & - \\
\hline NPV & 91.67 & 81.3 & 82.3 & - \\
\hline DA & 95.08 & 82.2 & - & - \\
\hline
\end{tabular}

\section{Conclusion}

FNAC is an ideal tool for the diagnosis of malignant lesions in lymph nodes and helps in avoiding excision biopsy. FNAC has high sensitivity and specificity in differentiating benign lesions from malignant ones. The present study showed inflammatory lesions as the major cause of lymphadenopathy in younger age groups and metastatic malignancies as the major cause in the elderly. Low-grade lymphomas were mistaken for non-neoplastic conditions in cases with no clinical suspicion of malignancy. The age, clinical findings, and supporting investigations should be taken into account while diagnosing a lesion as benign or malignant.

\section{What does the study add to existing knowledge}

FNAC as a diagnostic tool enables the diagnosis of inflammatory and neoplastic conditions without resorting to more invasive procedures.

The early stages of tuberculous lymphadenitis have been found to present with suppuration alone. The lack of granulomas should not rule out the possibility of tuberculosis.

Metastatic malignancy is an important cause of lymphadenopathy in the elderly population. 
Squamous cell carcinoma especially should be ruled out in case of cervical lymph node enlargement in this age group.

\section{Author's contributions}

Dr. Annu Elizabeth Prakash: Conceptualization, data collection, analysis, writing the original draft.

Dr. Navya Narayanano: Data collection, analysis, revising the draft, supervision

\section{Dr. Siyad Pokkakillath Mohamed: Conceptualization, data collection, resources, revising the draft}

Dr. Rasmi Unnikrishnan: Data collection, methodology, writing the original draft

\section{Reference}

01. Meenakshisundaram K, Rajeswari K, Rajalakshmi V. Diagnostic accuracy of Fine needle aspiration cytology in lymphadenopathy - our experience in a tertiary care hospital. Indian J Pathol Oncol. 2016;15(3)82-85.

doi: $10.5958 / 2394-6792.2016 .00017 . X$ [Crossref]

02. Upadhyay GP, Thakker RM. Evaluation of fine needle aspiration cytology as the initial diagnostic test in cases of cervical lymphadenopathy. Int $\mathrm{J}$ Res Med Sci. 2016;4(12)5103-5107.

doi: $10.18203 / 2320-6012 . i j r m s 20164066$ [Crossref]

03. Qadri SK, Hamdani NH, Shah P, Baba KM. Metastatic lymphadenopathy in Kashmir valleya clinicopathological study. Asian Pac J Cancer Prev. 2014;15(1)419-422.

doi: $\quad$ 10.7314/APJCP.2014.15.1.419 [Crossref]

04. Vimal S, Dharwadkar A, Chandanwale SS, Vishwanathan V, Kumar H. Cytomorphological study of lymph node lesions- A study of 187 cases. Med J Dr D Y Patil Vidhyapeeth. 2016;9(1)43-50.

doi: $10.4103 / 0975-2870.172428$ [Crossref]

05. Malhotra AS, Lahori M, Nigam A, Khajuria A. Profile of lymphadenopathy- An institutional based cytomorphological study. Int J App Basic Med Res. 2017;7(2)100-103.

doi: 10.4103/2229-516X.205812 [Crossref]
06. Nidhi P, Sapna T, Shalini M, Gupta K. FNAC in Tuberculous Lymphadenitis- Experience from a Tertiary Level Referral Centre. Indian J Tuberc. 2011;58(3)102-107.

[Crossref]

07. Chakravarty-Vartak US, Vartak SS, Nichat PB. Metastatic Lymphadenopathy by Fine-needle Aspiration Cytology. Int J Sci Stud. 2016;4(3)192-196.

doi: $10.17354 /$ ijss/2016/350 [Crossref]

08. Ageep AK. Assessment of Adult Peripheral Lymphadenopathy in Red Sea State, Sudan. Int J Trop Dis Heal. 2014;2(1)24-32.

doi: 10.9734/IJTDH/2012/1008 [Crossref]

09. Hemalatha A, Shruti PS, Kumar MU, Bhaskaran A. Cytomorphological Patterns of Tubercular Lymphadenitis Revisited. Ann Med Health Sci Res. 2014;4(3)393-396.

doi: 10.4103/2141-9248.133466 [Crossref]

10. Bhosale AA, Munavarah SA, Jeybalan N. Fine needle aspiration cytomorphological spectrum (FNAC) of peripheral lymph node lesions at a tertiary care Teaching medical college \& hospital. Indian J App Res. 2019;9(3)35-36.

[Crossref]

11. Stewart CJ, Duncan JA, Farquharson M, Richm ond $\mathrm{J}$. Fine needle aspiration cytology diagno sis of malignant lymphoma and reactive lympho id hyperplasia. J Clin Pathol. 1998;51(3)197-203. doi: $10.1136 /$ jcp.51.3.197 [Crossref]

12. Koo V, Lioe TF, Spence RA. Fine needle aspiration cytology (FNAC) in the diagnosis of granulomatous lymphadenitis. Ulster Med $\mathrm{J}$. 2006;75(1):59-64.

[Crossref]

13. Wilkinson AR, Mahore SD, Maimoon SA. FNAC in the diagnosis of lymph node malignancies: $A$ simple and sensitive tool. Indian J Med Paediatr Oncol. 2012;33(1):21-24. doi: 10.4103/0971-5851.96964 [Crossref]

14. Konar K, Ghosh S, Ghosh T, Bhattacharya S, Sanyal S. Pitfalls in the cytodiagnosis of metastatic squamous cell carcinoma in the head and neck- A retrospective study. J Cytol. $2008 ; 25(4) 119-122$.

doi: 10.4103/0970-9371.50795 [Crossref] 
15. Avninder S, Rakheja D, Bhatnagar A. Clear cell odontogenic carcinoma- a diagnostic and therapeutic dilemma. World J Surg Onc. $2006 ; 4 ; 91$.

doi: 10.1186/1477-7819-4-91 [Crossref]

16. Ghartimagar D, Ghosh A, Ranabhat S, Shrestha MK, Narasimhan R, Talwar OP. Utility of fine needle aspiration cytology in metastatic lymph nodes. J Pathol Nepal. 2011;1(2)92-95.

doi: 10.3126/jpn.v1i2.5399 [Crossref]

17. Chakrabarti P R, Varma A, Kiyawat P, Gupta K. Cytological Diagnosis Of Metastatic Melanoma- A Case Report. Indian J Pathol Oncol. 2015;2(2)84-86.

doi: 10.18231 [Crossref]
18. Kamaal M, Maheshwari U, Dhar R. Diagnostic Value of Fine Needle Aspiration Cytology in Enlarged Cervical Lymph Nodes in a Tertiary Care Hospital in Navi Mumbai, Maharashtra, India. J Med Sci. 2017;4(4)160-163.

doi: $\quad 10.5005 /$ jp-journals-10036-1163 [Crossref]

19. Hirachand S, Lakhey M, Akhter J, Thapa B. Evaluation of fine needle aspiration cytology of lymph nodes in Kathmandu Medical College, Teaching hospital. Kathmandu Univ Med J (KUMJ). 2009;7(26)139-142.

doi: $10.3126 /$ kumj.v7i2.2707 [Crossref]

20. Hafez NH, Tahoun NS. Reliability of fine needle aspiration cytology (FNAC) as a diagnostic tool in cases of cervical lymphadenopathy. J Egypt Natl Canc Inst. 2011;23(3)105-114. doi: 10.1016/j.jnci.2011.09.009 [Crossref] 